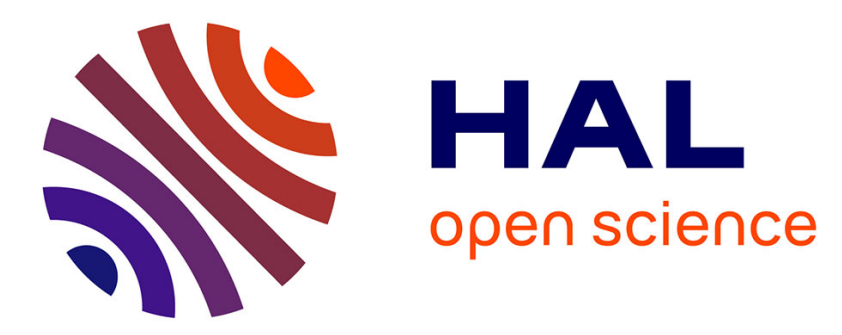

\title{
Sunlit soil surface extraction from remotely sensed imagery of perennial, discontinuous crop areas; the case of Mediterranean vineyards
}

Tom Wassenaar, Frédéric Baret, Jean-Marc Robbez-Masson, Patrick Andrieux

\section{- To cite this version:}

Tom Wassenaar, Frédéric Baret, Jean-Marc Robbez-Masson, Patrick Andrieux. Sunlit soil surface extraction from remotely sensed imagery of perennial, discontinuous crop areas; the case of Mediterranean vineyards. Agronomie, 2001, 21 (3), pp.235-245. 10.1051/agro:2001120 . hal-00886114

\section{HAL Id: hal-00886114 \\ https://hal.science/hal-00886114}

Submitted on 1 Jan 2001

HAL is a multi-disciplinary open access archive for the deposit and dissemination of scientific research documents, whether they are published or not. The documents may come from teaching and research institutions in France or abroad, or from public or private research centers.
L'archive ouverte pluridisciplinaire HAL, est destinée au dépôt et à la diffusion de documents scientifiques de niveau recherche, publiés ou non, émanant des établissements d'enseignement et de recherche français ou étrangers, des laboratoires publics ou privés. 


\title{
Sunlit soil surface extraction from remotely sensed imagery of perennial, discontinuous crop areas; the case of Mediterranean vineyards
}

\author{
Tom WASSENAAR $^{\mathrm{a} *}$, Frédéric BARET ${ }^{\mathrm{b}}$, Jean-Marc RoBbeZ-MASSON $^{\mathrm{a}}$, \\ Patrick ANDRIEUX ${ }^{\mathrm{a}}$ \\ a UMR Sol et Environnement INRA-ENSA, 2 place Pierre Viala, 34060 Montpellier Cedex 02, France \\ ${ }^{\mathrm{b}}$ INRA Bioclimatologie, Domaine St. Paul, Site Agroparc, 84914 Avignon Cedex 09, France
}

(Received 3 August 2000; revised and accepted 6 January 2001)

\begin{abstract}
In the Mediterranean wine producing region, soil surface remote sensing for hydrological modelling is hampered by the discontinuous canopy of the perennial vine stocks. Very high spatial resolution imagery allows the recording of ground resolution elements that comprise only soil in between vine stocks. To enable the comparison of the resolution element's spectral properties with known bi-directional properties of different types of soil surface, pixels representing the pure and sunlit soil surface have first to be extracted from the imagery. Multi-scale analysis proved to provide a robust and satisfactory segmentation method. Conditional per-field adjustment of a multi-scale image mask allows the extraction of the image segments corresponding to the sunlit soil surface, whatever its state or composition. Moreover, the vegetation cover can be estimated with an error of at most $10 \%$ if the geometric configuration is taken into account.
\end{abstract}

remote sensing / soil / vine / segmentation / multi-scale analysis

Résumé - Extraction de la surface du sol éclairée dans des images de télédétection de cultures pérennes et discontinues ; le cas du vignoble méditerranéen. En région méditerranéenne viticole, l'estimation des états de surface du sol par télédétection est perturbée par la présence d'un couvert végétal pérenne et discontinu. L'imagerie à très haute résolution spatiale permet d'obtenir des pixels constitués uniquement de la surface du sol. Pour comparer la radiométrie de ces pixels aux propriétés bidirectionnelles connues de différents types de surface, on cherche à isoler les pixels correspondant à la surface du sol éclairée. L'analyse multi-échelle fournit une approche de segmentation robuste et satisfaisante. L'ajustement conditionnel par parcelle d'un masque obtenu par analyse multi-échelle permet d'accéder à la surface du sol éclairée, indépendamment de son état ou de sa composition. De plus on peut estimer le couvert végétal de la vigne avec une marge d'erreur de $10 \%$ si la configuration géométrique est prise en compte.

télédétection / sol / vigne / segmentation / analyse multi-échelle

Communicated by Gérard Guyot (Avignon, France)

* Correspondence and reprints

wassenaar@ensam.inra.fr 


\section{INTRODUCTION}

Hydrological catchment studies have demonstrated the dominant influence of soil surface features and field structure on land surface flow [2, 18, 19] and pesticide transport [21] in the Mediterranean vineyard environment. Measuring soil surface feature variables at the scale of one or more catchments is required by spatially distributed hydrological models that help to understand and describe flooding events, agricultural pollution and water resource management.

For agricultural areas with spatially continuous crops, remote sensing has proven to provide such information for various surface feature variables. Reviews like Blanchard et al. [5] and Van de Griend and Engman [31] summarise the results obtained over the last twenty years in remote sensing for hydrological modelling, mostly concerning progress in the detection of surface roughness, humidity and soil organic matter.

On the contrary, little effort has been directed to the analysis of discontinuous crops such as vineyards using remote sensing. Most studies applied to vineyards are focusing on the crop rather than on the underlying soil surface. They generally exploit the spectral features of the radiometric signal, ignoring the influence of the spatial discontinuity [6, 16, 24, 30, using Landsat TM, 33].

Few studies have assessed the soil surface signal under vineyards. Hill et al. [14] used AVIRIS data in an environmental study to estimate the soil erosion risk of Mediterranean vineyards using spectral unmixing techniques at a spatial resolution of $20 \mathrm{~m}$. Company et al. [8, 9] used airborne SAR and ERS data to describe soil surface roughness under Mediterranean vines. They were severely hampered by the effect of vine rows and their compass orientation on radar backscatter. It follows from these studies that satisfactory results may only be expected by directly assessing the soil surface signal.

In the following an automated method is proposed to extract for vineyard fields the sunlit soil surface in between the vine stocks during the growing season on the basis of very high spatial resolution images.

\section{STUDY AREA}

The experiment took place within the lower La Peyne catchment $\left(43^{\circ} 30^{\prime} \mathrm{N}, 3^{\circ} 20^{\prime} \mathrm{E}\right)$. La Peyne river is a tributary of the coastal river Hérault and located in the Hérault province, Southern France, about $60 \mathrm{~km}$ west of Montpellier. This catchment of about $70 \mathrm{~km}^{2}$, strongly dominated by vine cultivation (about $70 \%$ of the total surface), is representative of the French Mediterranean coastal plain with respect to geology, geomorphology, agricultural practices, vineyard management and vine species. The sites studied (four sites of about $1.5 \mathrm{~km}^{2}$ each) cover the variability in physical characteristics and cultural practices.

Vineyard fields in the coastal plain range in size from 0.05 ha to about 3 ha, where the small ones occupy most of the surface. Every field is subject to different agricultural practices due to its location, water availability, orientation, vine species and variety, site quality, farmer's conviction and many social and economic factors. This variety of practices includes within fields heterogeneity: rows can be grouped into blocks, and soil in-between rows in ploughed fields can selectively be left untouched.

This leads to an important variation of soil surface spectral properties between and often also within fields. Other factors not related to human activity still increase this variation: pedological and geological variations can have an impact on surface reflectance; between and within fields, weeds can be at different stages of colonisation.

The vine training mode also varies between fields. Champagnol [7] recognises nine main types of vine geometry, four of which are common to the Mediterranean region. From a hydrological point of view, three of these (cylinder, reversed cone and hemisphere) can be regrouped under the common name of "goblet", i.e. individual plants distributed over a square grid pattern without any guiding support. This is the traditional training mode throughout the Mediterranean region. The other common spatial training mode is called "wire-trained", i.e. rows of plants growing along two or more horizontal metal wires, their shoots providing a continuous cover along the wire (Fig. 1).

Apart from vine, some continuous crops like winter wheat and rape can be found. Fallow fields are frequently

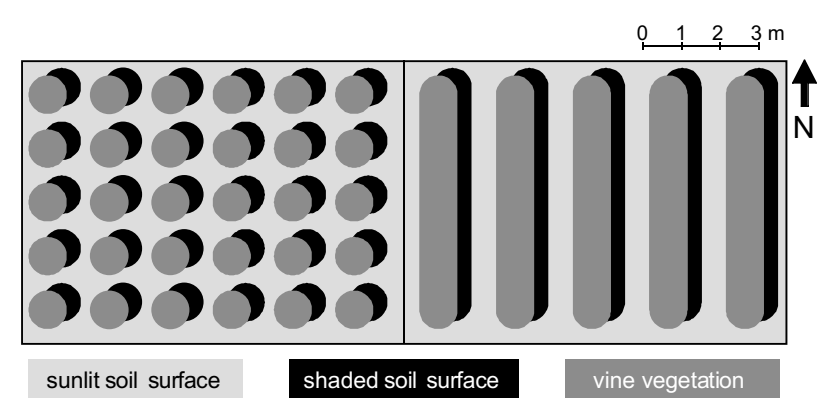

Figure 1. Schematic vertical view of a goblet (left) and wiretrained (right) vineyard, showing the three main objects of the image. Solar azimuth south-west. 
encountered, but more and more replanted with vine. A few orchards can also be found. These types of land cover have been identified in the images as being different from vine thanks to a per-field frequency analysis [32] and will not be considered in this paper.

\section{MATERIALS AND METHODS}

The choice of the spatial resolution is critical, because we need to spatially distinguish vine plants from the underlying shaded or sunlit soil (Fig. 1). The spatial resolution has to be consistent with the spatial frequency of the terrain [10]. As we know what frequencies we are looking for, statistical methods as proposed by Atkinson and Curran [3] have not been considered. To assure full contrast in the measurements in the image, the sampling theorem states that a resolution-cell size lower than half the size of the objects in the scene is necessary [35]. During the growing season, vine rows are roughly 0.5 to $1 \mathrm{~m}$ wide. To distinguish accurately the sunlit soil surface under all geometric illumination and view conditions, the optimal spatial resolution was therefore taken to be about $0.25 \times 0.25 \mathrm{~m}$. This pixel size is lower than $0.8 \mathrm{~m}$, i.e. the highest spatial resolution currently available from commercial space sensors $[1,4,28]$. Therefore aerial photography has been used. This choice of the spatial resolution also compromises between the resolving power of the film and the scanning resolution on one side, and on the swath to be covered ( 1.5 by $1.0 \mathrm{~km}$ per picture) on the other side.

The aerial photography limits the spectral information to three relatively broad bands. True colour was preferred to infrared film colour films for its high resolving power. Moreover near infrared was not used because it was not expected to help the sunlit soil segmentation as discussed later, and the indirect illumination of the soil surface by the vine vegetation was expected to hamper analysis in later stages.

Orthogonal photographs were taken from a Hughes 300 helicopter at an altitude of about $1100 \mathrm{~m}$ by a Canon EOS 500 camera with $35 \mathrm{~mm}$ lens ( $\varnothing 58 \mathrm{~mm}$ ), using Fujichrome Provia 100 RDP II colour film. The pictures were scanned by a Nikon LS-1000 slide scanner at maximum resolution (2700 dpi, i.e. a pixel size at ground of 20 to $25 \mathrm{~cm}$ ), radiometrically-corrected by the empirical line method [20], and geometrically corrected and assembled. For validation purposes, even higher spatial resolution images (a few centimetres) were taken at about $300 \mathrm{~m}$ altitude over a range of fields with varying soil surface state and geometric configuration. The images were processed using IDL/ENVI (Research Systems Inc., Boulder, Colorado) software package.
Digitised land register maps were used in the automatic per-field analysis procedure. Comparison with the precise digital geographic database of IGN (French National Geographic Institute) showed that field limits of these maps were of sufficient quality to allow their use for the extraction of the fields image information.

\section{PROPOSED IMAGE PROCESSING STRATEGY}

\subsection{Requirements to be fulfilled by the method}

The method to be developed to extract accurately the sunlit soil fraction from the images described above under all conditions encountered, needs to fulfil a number of requirements:

1. it must be independent of the absolute reflectance values because soil surface resolution elements can have similar spectral response with respect to vine resolution elements and because soil surface and vine reflectance vary between and within vineyards (Fig. 2);

2. the procedure to be selected needs to be contrast invariant as shown by Figure 2;

3. the result's quality should be independent of the plantation structure's orientation. The procedure should therefore be rotation invariant;

4. the method should be shape invariant to work both on goblet and on wire-trained vineyards;

5. it should be invariant to translation;

6. the method should accurately extract the part of the image corresponding to the sunlit soil surface, irrespective of the relative fractions covered by sunlit and shaded soil and vine. This distribution varies rapidly in time and space as a function of vine development and geometric configuration.

\subsection{Selection of spectral input}

From the three fractions considered (sunlit soil surface, shaded soil surface and vine vegetation), the first has to be isolated. Band ratios like vegetation indices [20] are unsuitable because they can be similar for vine and green grass-covered sunlit soil. Figure 3 shows that the reflectance intensity in the red channel provides the best input, irrespective of the spectral information available: with respect to the near infrared reflectance in the standard case as represented by this figure, i.e. a "naked" non-vegetated mineral soil-surface between the vine stocks, we note that the shaded side vine reflectance is lower than the sunlit side. In turn the sunlit side 

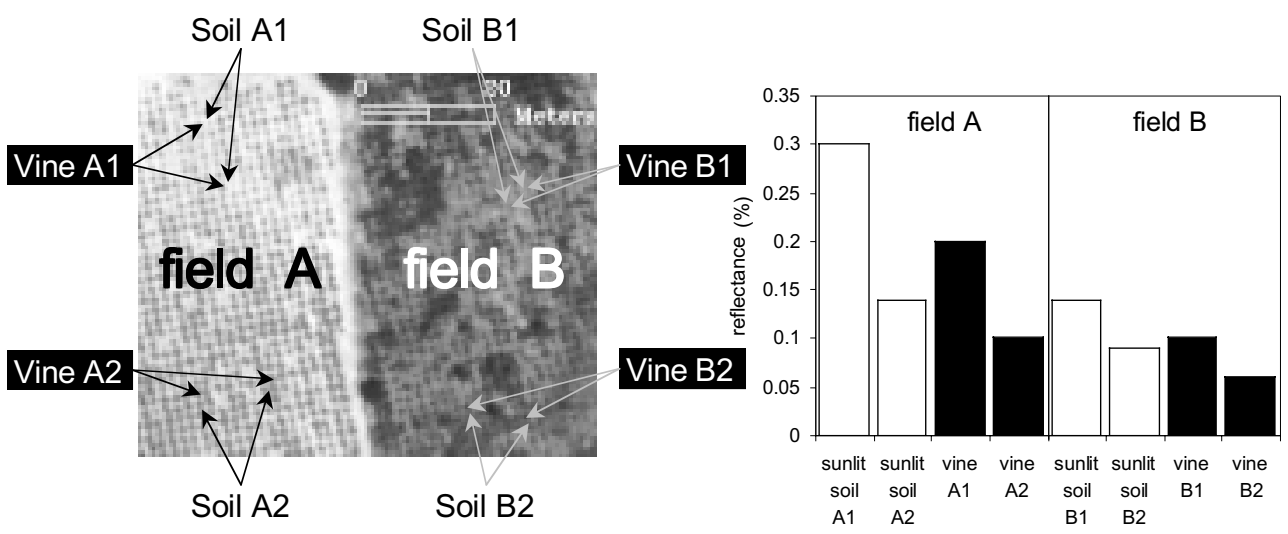

Figure 2. Between and within field reflectance variation. The image sample shows the red $(650 \mathrm{~nm})$ reflectance in May 1998 for a few pixels of two juxtaposed vineyards, the one on the left (A) with mainly bare calcareous soil, and the one on the right (B) covered with weeds. Shadowed surfaces have not been considered in this illustration. From the pixel reflectance values (graph on the right) it can be seen that neither a general, nor a field specific threshold allows us to distinguish between the objects sunlit soil and vine.

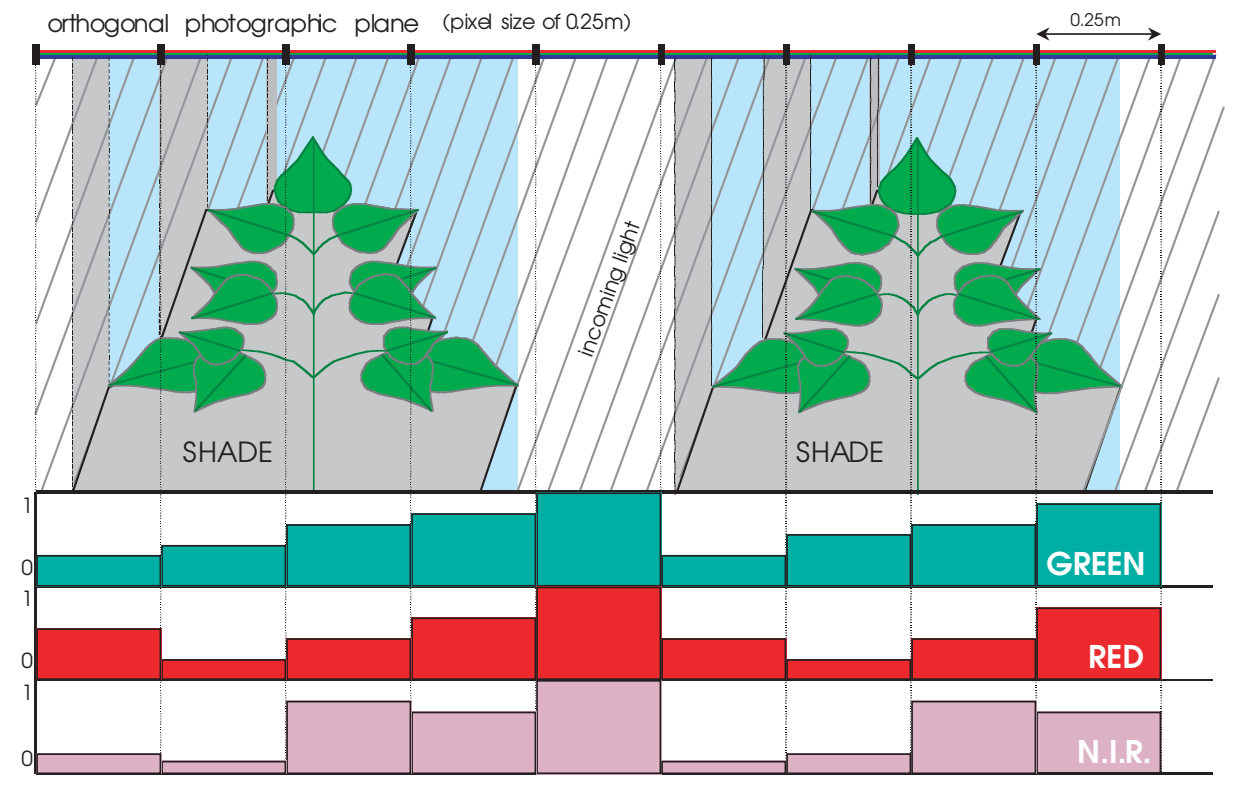

Figure 3. Schematic vine, shade and soil contributions to the canopy reflectance under a solar zenith angle around noon in summer in the Mediterranean region $\left(20^{\circ}\right)$, NIR $=$ near infrared.

reflectance may not be significantly higher than the response of a bright, crusted mineral soil, because of a possibly important fraction of shade between leaves within a sunlit vine pixel. Therefore the response of the near infrared channel is considered to be unsuitable as a discriminator, which justifies the use of the regular colour film as stated earlier. The response in the green band will be comparable between the shaded vine and shaded soil, and also between the sunlit vine and sunlit soil. Therefore, masking based on the green band would be shifted from the actual sunlit soil, resulting in a contaminated sunlit soil surface portion. The red reflectance of vine is low, even on the sunlit side, and does not exceed the sunlit soil surface reflectance even where the 
last one is covered by grasses or crop residues. This information has therefore been selected as input for the method developed.

\subsection{Selection of segmentation approach}

The requirements specified in paragraph 4.1 clearly show that traditional spectral thresholding does not provide an adequate solution to the problem. Even results from adaptive thresholding [15] techniques are not satisfactory: local histograms do not allow for robust determination of a threshold because of the relatively important transitional zones between the objects; these techniques are not contrast invariant and may mix up vine and grass covered soil. A spatial segmentation operation is required. Two traditional approaches exist [25, 34]: detection of edges and growing regions from seed points. Edge detection techniques have important drawbacks that are incompatible with our requirements: they are very sensitive to thresholds [34] and often detected boundaries are not closed [11]. Spectral variations within the sunlit soil surface would surely lead to many false edges. The same applies for region growing techniques, their results depending to a large extent on the seed point selection.

Other categories of textural image segmentation approaches exist, like image pyramids and random fields [26]. Innumerable other (hybrid-)techniques have been developed. One might think that for example local minima detection might help us out, but again a lack of robustness is found. To obtain satisfactory results, an image texture model approach is required, because it allows to incorporate the concept of "object" [23]. This excludes the use of statistical texture analysis techniques as proposed by Haralick [13].

The texture model here is easily obtained by combining Figures 1 and 3. A "top-down" [26] definition can be given, claiming that there is a basic texture element, called a texel, and a placement rule. There are only two objects of interest: the sunlit soil surface, and the vine with its shadow. The sunlit soil surface is expected to be always at least slightly brighter than vine and/or shadow pixels. The object "vine with shadow", of variable but very limited size (size criteria $\mathrm{C}_{\text {size }}$ of the model: about 2 to 5 pixels wide and undetermined length) and very regular spacing (spacing criteria $\mathrm{C}_{\text {spacing }}$ of the model: the centres of two identical and adjacent objects are 6 to 10 pixels apart), is superimposed on the soil surface background, having itself an internal variability at different scales. In-between these two objects we find an important fringe of mixture pixels smoothing the borders.
Clearly such a model as a basis for segmentation would provide erroneous results on fields other than vineyards, but those have been eliminated beforehand [32].

The "vine with shadow", object can best be isolated from its background by a method taking profit from this specific size and spacing, i.e. multiresolution analysis. Belonging to the image pyramids category, multiresolution analysis [22] results from the embedded subsets generated by interpolations at different scales. Our object being coarser than the single pixel resolution, a smoothing is required to make the object stand out [Morel, personal communication, 27]. The much coarser resolutions on the contrary, showing the low frequency variations, are not of interest for this problem.

\subsection{Method description}

\subsubsection{Object identification}

A reliable identification of the object now depends on the selected scale and smoothing approach. Over the last decades a lot of interest has been put on obtaining the information at different scales by wavelet transforms. In our case however a multiresolution approach based on the median transform as proposed by Starck et al. [29] is expected to provide better results for a number of reasons.

There are several problems related to the wavelet transform: point objects pollute all scales, a positive structure at a scale is surrounded by negative values complicating the analysis, and there is no ideal wavelet transform algorithm. Among the advantages for object detection provided by the median filter we note: a robust smoothing due to its nonlinearity (i.e. the effects of outlier pixel values are mitigated); shapes of structures in the scales being closer to those in the input image than would be the case with a wavelet transform; and the results of the median filter are found to be better than those from other morphological tools [29]. So it creates level sets without smoothing edges and it avoids curvature motion of straight sections [12].

The object "vine and shadow" can now be identified, not by delimiting a given level set at a certain scale, but by looking at the change in level sets upon change of scale. The difference between the scales obtained by smoothing with a $3 \times 3$ pixel and a $5 \times 5$ pixel median filter (Fig. 4) appears to best delimit our object. The smallest window, needing to be as small as possible regarding the often small width of the object, provides the level sets delimiting the object. The larger window rises the level sets of the object "vine with shadow" by 


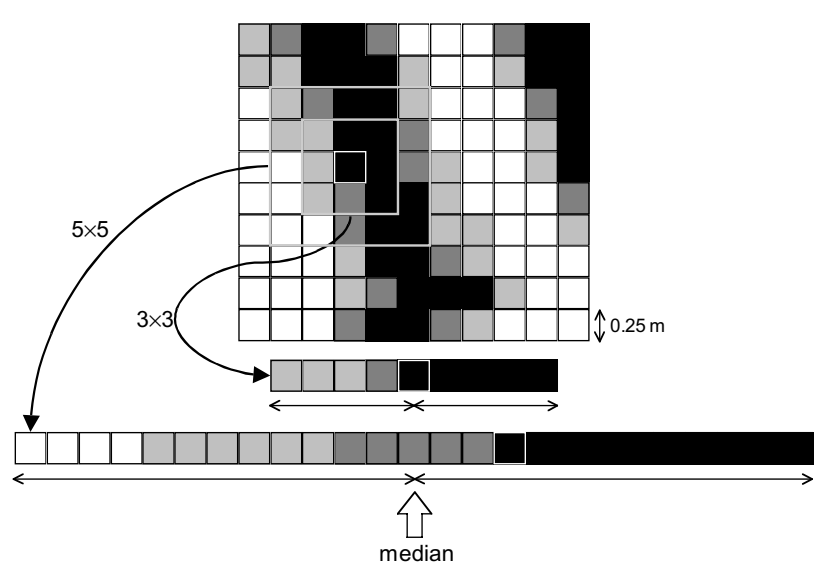

Figure 4. Schematic illustration of the result of a $3 \times 3$ and $5 \times 5$ median filter on a red channel vine pixel (black, the example centre pixel having a white contour). Sunlit soil is represented by white cells and the transitional fringe by light and dark grey cells. The schematic image fragment represents part of a theoretic red channel response on a wire-trained vineyard. The bars show the filter pixels in an ordered manner.

incorporating edge information in the centre of the object and sunlit soil information near the edge of the object. At the same time level sets of the object "sunlit soil" are lowered by inclusion of edge information in the centre and vine or shadow information near the edge (Figs. 5 and 6). Coarser resolutions (larger smoothing filters) approach the object spacing and therefore may lead to inclusion of two copies of the counter object, degrading the object in-between. Upon further resolution decrease, the two objects will dissolve into each other or, even worse, will be inverted.

In short, a boolean image, indicating the location of the objects, is obtained by the following rule:

$$
\begin{gathered}
\text { "vine and shadow" pixel }= \\
\text { where }(5 \times 5 \text { median filtered image -- } 3 \times 3 \text { median } \\
\text { filtered image })>0 \text {. }
\end{gathered}
$$

Such an image, still containing a few "islands" of wrongly classified pixels within both objects, is cleaned by a 3 $\times 3$ median filter, eliminating isolated pixels while preserving the object's shape [29]. Other cleaning techniques like combined opening-closing [27] are neglected because they affect the object's shape and simply because the pixel size does not allow the definition of a structuring element small enough to clean without damaging the small objects.

\subsubsection{Object delimitation}

The spacing criteria $\left(\mathrm{C}_{\text {spacing }}\right)$ used by the image texture model are very stable throughout the images. The size criteria $\left(\mathrm{C}_{\text {size }}\right)$ may however be too restrictive with

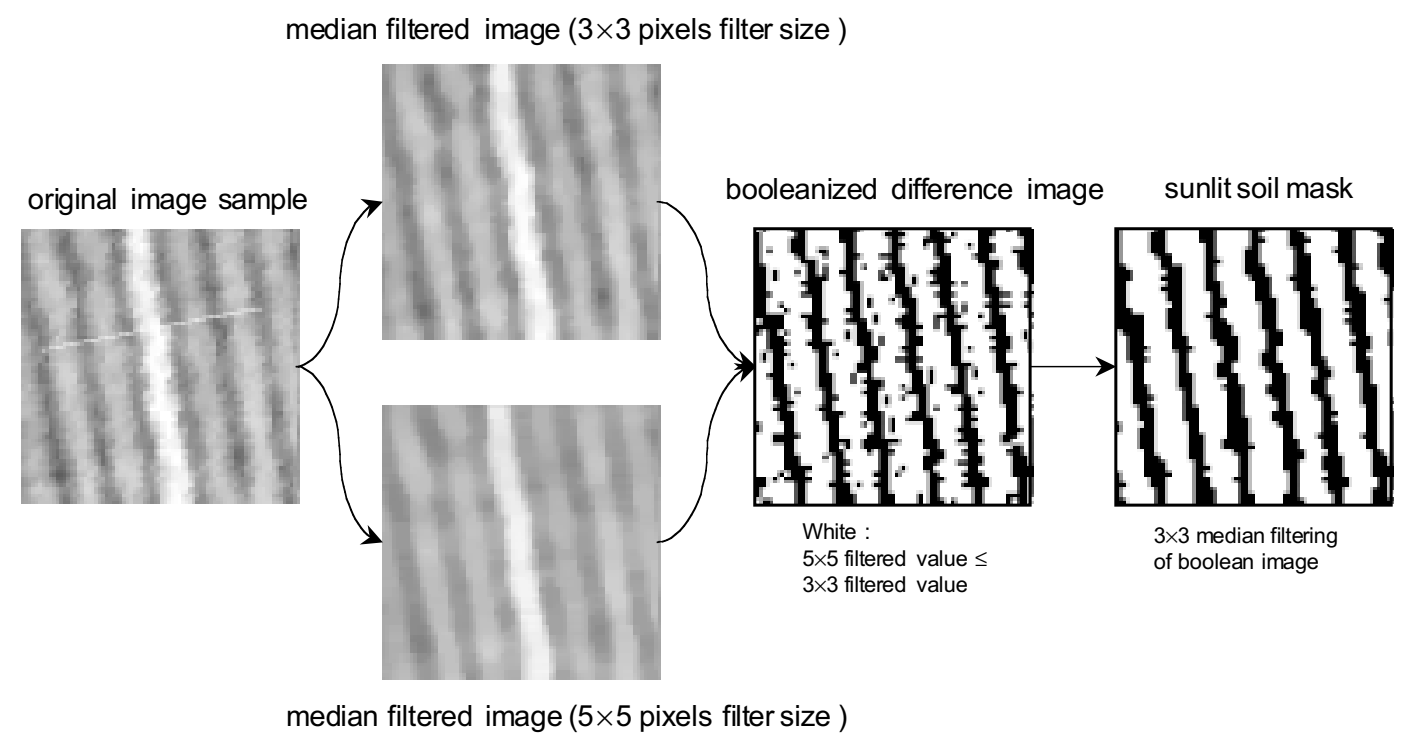

Figure 5. Illustration of the sunlit soil recognition method on a ploughed wire-trained vineyard sample (May 1998) containing a nonploughed inter-row. The white line in the original image sample (red band) presents the location of the cross section of Figure 6. 


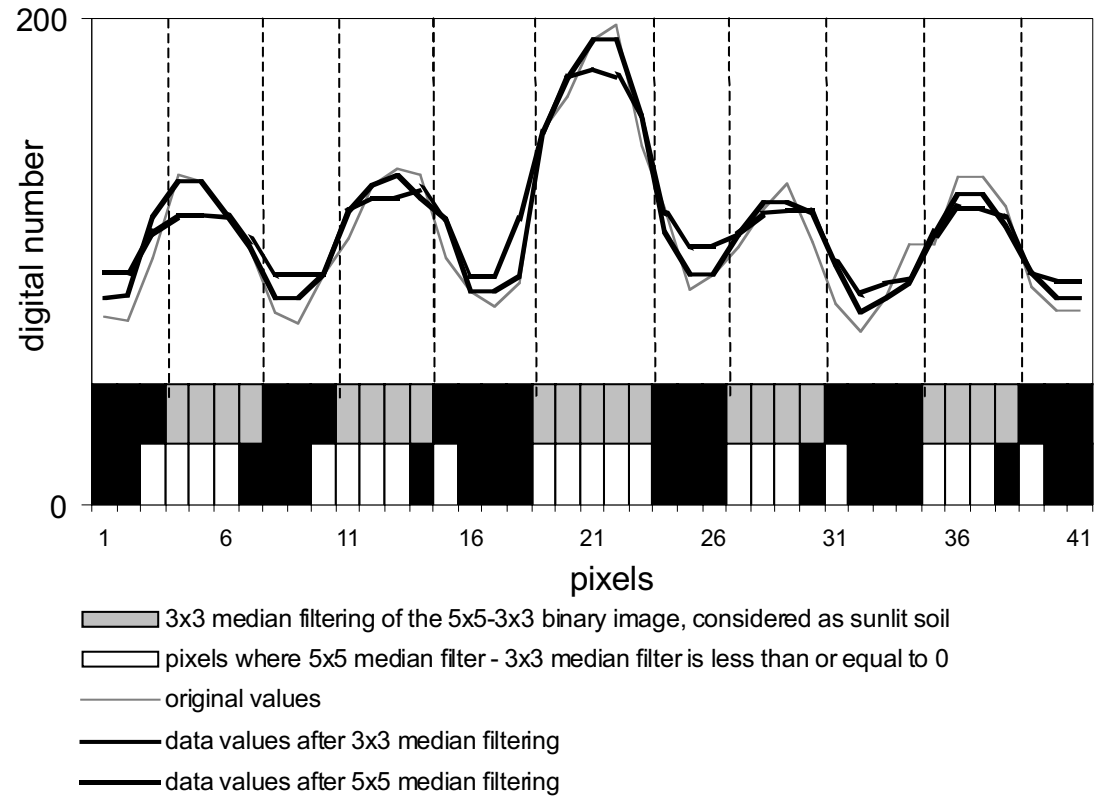

Figure 6. Cross section (see Fig. 5) showing the original pixel values (red band) and their change upon two dimensional median filtering (line graphs). The black and white/grey bars correspond resp. to the black and white pixels of the corresponding procedure steps in Figure 5. respect to the variety of situations encountered in the image, due to the dependency upon the geometric configuration (slope, row orientation, viewing and sun angles). The now located objects have to be more carefully delimited, so as to avoid as much as possible a contamination of the sunlit soil surface signal by vine or shadow. We therefore apply a "conditional erosion/dilation" (Fig. 7): the "vine with shadow" mask obtained is deliberately eroded (Minkowski substraction) and dilated (Minkowski addition) [27], and the situation with the highest radiometric contrast between the underlying pixel populations of the two objects is selected as being the best delimiting mask. If this implies a change, the procedure is repeated in that direction, until the maximum contrast has been found. A few remarks have to be made with respect to this conditional erosion/dilation.

\subsubsection{Structuring element}

Even the smallest, non-orientation selective, structuring element will lead to a two pixel reduction (one on each side), i.e. $0.5 \mathrm{~m}$, of the row width upon erosion. This is an important change of the object's width. To somewhat reduce this change step a "shapeless" structuring element is introduced: its shape adjusts to the shape of the edge and only if its total size (any 7 cells out of the 9 cells of a $3 \times 3$ window) does not fit in, the central pixel is eroded. This change in structuring element, with respect to the smallest possible fixed shape element, has no effect on straight or convex edge sections, but avoids erosion at concave sections, i.e. where the blobs are thinnest and less "in need" of an erosion (Fig. 7). The dilation is obtained in the opposite way.

\subsubsection{Contrast change}

Many different statistical descriptors could be applied here, but the simple measure of the change in difference between the median values of the two populations appeared satisfactory. The contrast is expected to be highest when both objects include part of the border pixels, i.e. the pixels containing a fraction of sunlit soil and a fraction of shadow and/or vine (Fig. 7). To avoid an increase in the contamination of the "sunlit soil surface" pixel population, the object of interest, an additional condition inhibits dilation of the sunlit soil surface image segments if this results in a significant ( $\alpha=0.10$, empirically determined) increase of the internal radiometric variation.

\section{ACCURACY ASSESSMENT AND DISCUSSION}

The visual qualitative inspection of the results obtained on the image mosaics of the four study sites on two dates (May and June 1998) shows very good performances of the method which are independent of vine training mode. The procedure also seems to comply with other robustness criteria, like the independence to 


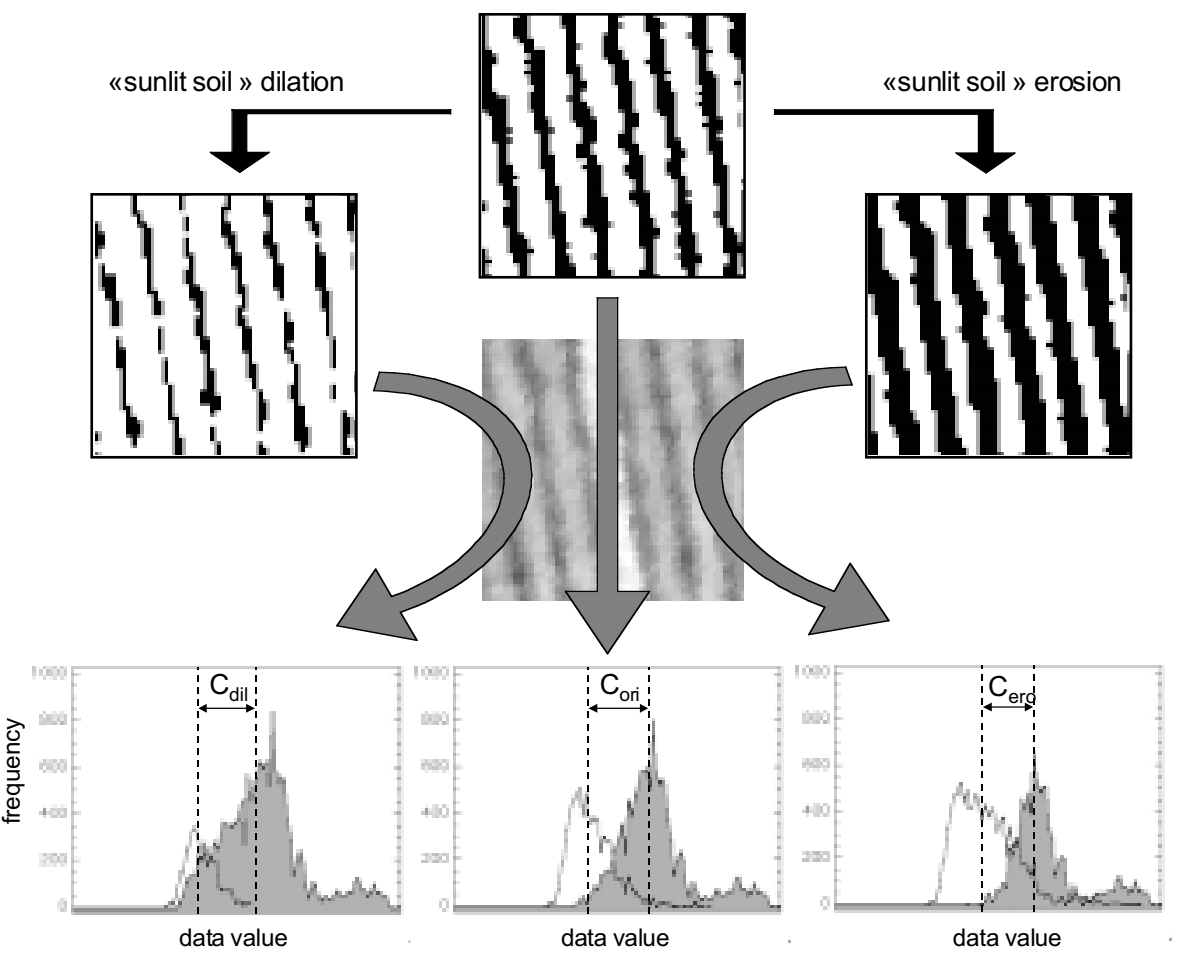

Figure 7. Illustration of the object delimitation by conditional erosion/dilation. The grey (resp. white) histograms correspond to the region covered by the white pixels (resp. black). The contrast between the two pixel populations obtained by application of the original $\left(\mathrm{C}_{\text {ori }}\right)$, the dilated $\left(\mathrm{C}_{\mathrm{dil}}\right)$ and the eroded $\left(\mathrm{C}_{\text {ero }}\right)$ mask is indicated. In this example the original mask fits best (highest contrast). The dilated mask case shows a significant increase in variation within the "sunlit soil" pixel population.

absolute radiometric values and their variation as illustrated by the non-ploughed inter-row in Figure 5.

Precise ground truth vegetation cover information or highly accurate validation data sets are nearly impossible to obtain, thereby limiting the quantitative evaluation of the method. However, an approximation of such an accuracy assessment has been obtained in the following way: some low altitude images were acquired during a special accuracy assessment campaign (May 1999) to obtain very high resolution images. On these scanned images (Fig. 8), the sunlit soil was manually extracted by onscreen digitalisation. Then the images and their manually produced masks were spatially degraded to a $0.25 \mathrm{~m}$ resolution. After applying the automatic segmentation method to the $0.25 \mathrm{~m}$ resolution images, its accuracy is assessed by comparison with the $0.25 \mathrm{~m}$ resolution degraded manually digitised mask. This assessment results in an approximation, because the manual segmentation is not perfect and its spatial degradation induces additional error. Moreover the spatial resolution of the very high resolution images remained limited (about $6 \mathrm{~cm}$ pixel size by flying at $250 \mathrm{~m}$ height), because at too low altitudes the within-field view angle variation is incompatible with the per-field mask adjustment (variable "vine and shadow" size).

Applying the method to a variety of image segments obtained at low altitude (Fig. 9) allows for a number of important observations. First of all we note that the method is robust with respect to crop orientation and training mode (goblet or wire-trained). If the manually produced masks are considered "true", we see that the vine and shadow cover estimation "error" generally remains below $10 \%$, except for some cases where visually relatively little vine and shadow have been identified. Most often (Fig. 9, lower right and upper row second from left), this is related to the security built into the method to avoid an increase of variance within the initial sunlit soil pixel population. As the change upon morphological erosion is relatively important, the gap between the delimitation retained and the ground truth can remain 


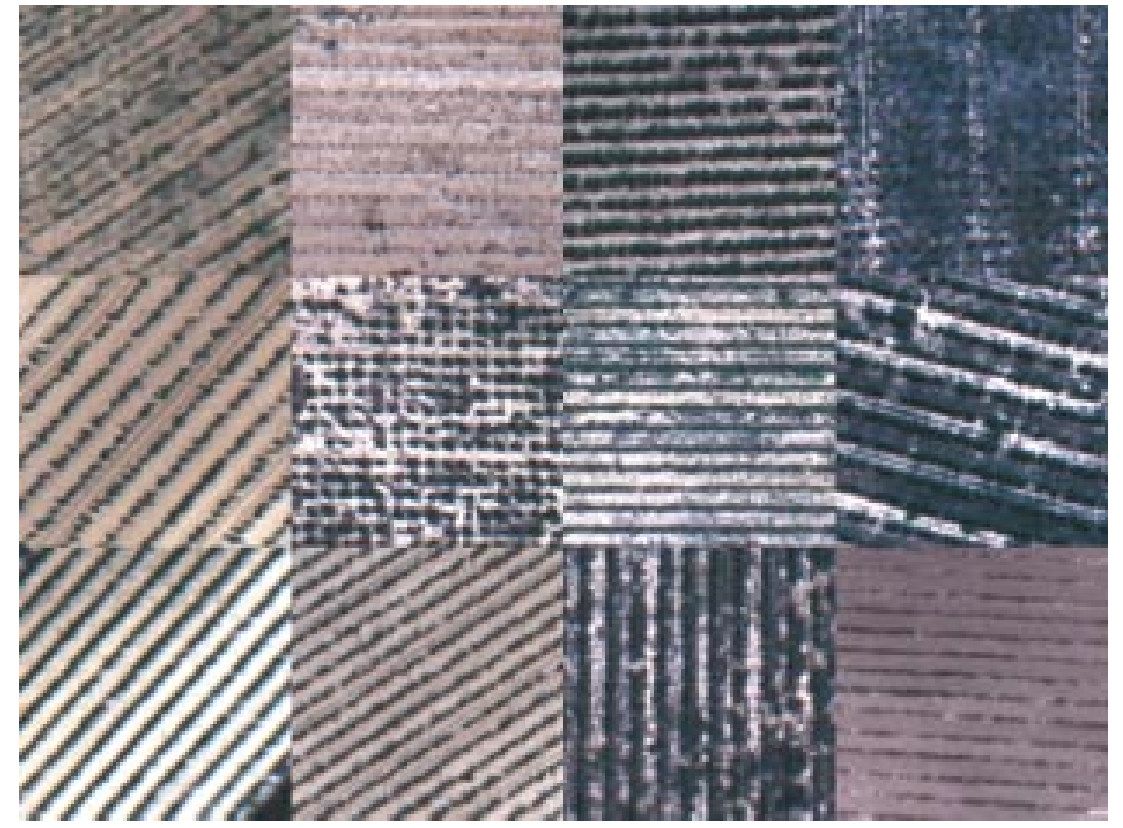

Figure 8. Mosaic with small parts of 12 different vine fields. The variation between these samples represents a large part of the between-field variation as found in the images due to varying geometric configuration (viewing, illumination, crop orientation), varying crop size, age and training mode, changes in soil and soil surface state.
Spatially degraded, manually digitised mask

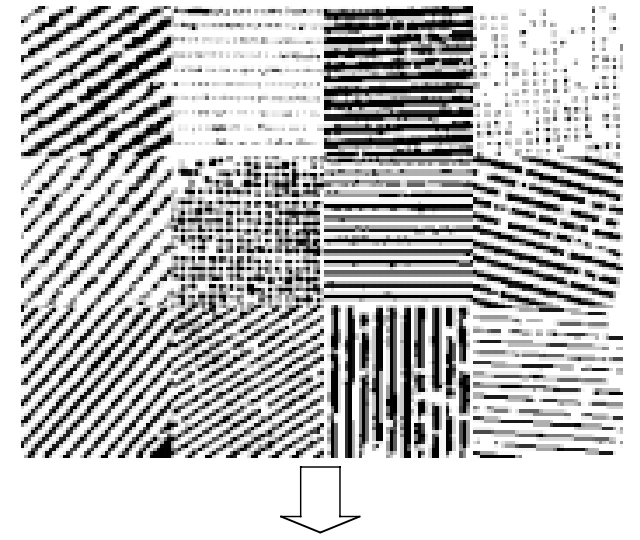

Per-field comparison of ground data and procedure output

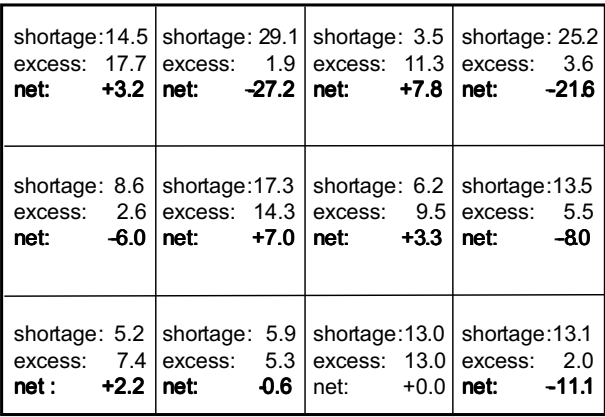

Object identification phase

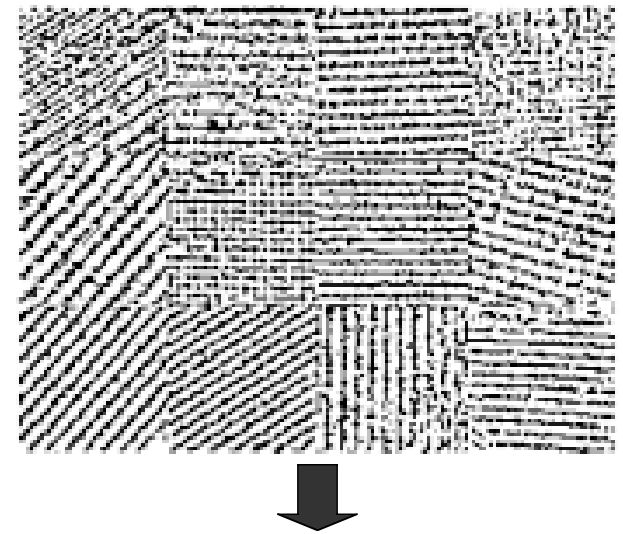

Per-field object delimitation phase

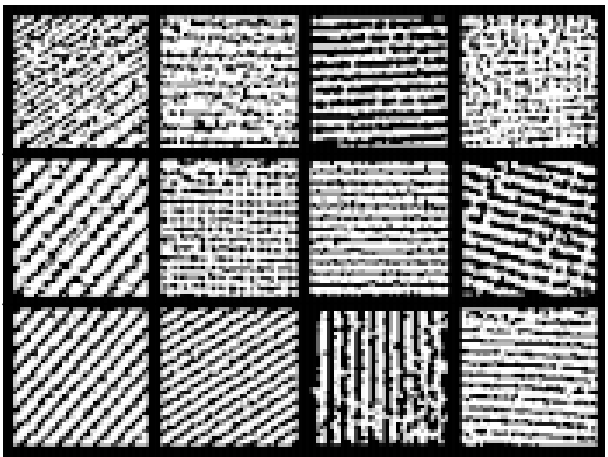

Figure 9. The application of the two steps of the procedure (see Figs. 5 and 7) on the image of Figure 8 are shown by the binary images on the right. The comparison between the final results and the manually produced ground data is shown by the table on the lower left side (each cell corresponding to the image sample at the same location in the mosaic): shortage is the percentage of pixels visually identified as sunlit soil and not recognised as such by the procedure, excess is the inverse and net their difference, i.e. the accuracy of the vine and shadow cover estimation. 
relatively important. In some cases imperfections in the manual digitisation contribute to an increase of the error: in the upper right sample (Fig. 9) several vines that could not be identified visually were detected by the automatic method.

Generally the absolute values of shortage and excess (Fig. 9) should not be considered as serious errors as long as their values are of the same order and do not exceed $15 \%$. The limited accuracy of the hand-delimited "ground truth" and the resampling method used for the spatial degradation (cubic convolution) can lead to a slight shift between the method's results and the reference mask, leading to a rapid increase in shortage as well as in excess. Only the upper left sample presents a real problem: the relatively wide spacing of the rows combined with dark lines in the middle of the inter-row forces the method to falsely identify vine in the interrow. Fortunately such cases are very scarce.

\section{CONCLUSION}

The segmentation of the sunlit soil surface pixels is required for two reasons. The main objective is to obtain a population of pixels that is representative of the sunlit soil surface's reflectance and variation. A secondary objective is the estimation of the field's vine vegetation cover. This would provide one of the input parameters required by the spatially distributed hydrological model [17].

With respect to this vegetation cover estimation we have noticed an overestimation of the vegetation cover on very young vine fields. This is not related to the impossibility of the method to produce a better delimitation, but is related to the prevalence of its calibration for the main objective. Model parameters can easily be adapted to produce an optimal mask.

Nevertheless it will remain a coarse approximation due to the relatively large cover change upon one step in the iterative erosion process. To improve the estimation of the vegetation cover, research effort should be put into the statistical analysis of the contrast change obtained over the successive erosions/dilations. The best "vine and shadow" delimitation can very well be situated inbetween two versions of the mask and even if the geographic delimitation cannot be obtained, its cover may still be quantitatively estimated. Once this estimation obtained, the orthogonal vine vegetation cover can be calculated by taking into account the shadow part. All parameters required for this calculation (geometric configuration of viewing and illumination, crop orientation, slope and aspect) are available except for the plant height that can vary from $1.20 \mathrm{~m}$ to $1.80 \mathrm{~m}$.
The most important and very satisfying result is that the method proposed allows for a rapid and unambiguous identification of the majority of the sunlit soil surface, independent of its radiometry and variation. The radiometry of the pixels labelled "sunlit soil surface" can now be compared to known bi-directional reflectance properties of a variety of soil surface states, and that is a big step towards recognition of the soil surface state under perennial, discontinuous crops.

Depending on the research objective the method can be inverted to obtain a pure crop signal by masking the soil "background". Shaded soil pixels then have to be eliminated from the "pure" shade and vine pixel population. The use of vegetation indices may encounter the same difficulties as those mentioned before (Sect. 4.2). Knowing the geometrical configuration (sun, view and slope azimuth and zenith angles, row orientation), a morphological approach could be developed.

\section{REFERENCES}

[1] Allan J., A new era for remote sensing and GIS, GIS Europe 5 (1996) 24-25.

[2] Andrieux P., Louchart X., Voltz M., Bourgeois T., Déterminisme du partage infiltration-ruissellement sur parcelles de vigne en climat méditerranéen, Documents du BRGM 256 (1996) 7-11.

[3] Atkinson P.M., Curran P.J., Choosing an appropriate spatial resolution for remote sensing investigations, Photogramm. Eng. Remote Sens. 63 (1997) 1345-1351.

[4] Barnsley M., Hobson P., Making sense of sensors, GIS Europe 5 (1996) 34-36.

[5] Blanchard E., King C., Le Bissonnais Y., Bourguignon A., Souchère V., Desprats J.-F., Maurizot P., Paramétrisation du potentiel de ruissellement des bassins versants au moyen de la télédétection et des systèmes d'information géographiques. Application à des bassins versants du Pays de Caux, Étude et Gestion des Sols 6 (1999) 181-199.

[6] Carothers J., The art of winemaking, Imaging Notes 15 (2000) 18-21.

[7] Champagnol F., Eléments de physiologie de la vigne et de viticulture générale, ISBN 2-9500614-0-0, Dehan, Montpellier, 1984, $351 \mathrm{p}$.

[8] Company A., Delpont G., Guillobez S., Arnaud M., Potentiel des données radar ERS-1 pour la détection des surfaces contributives au ruissellement dans les vignobles méditerranéens du Roussillon (France), in: 6th International Symposium "Physical Measurements and Signatures in Remote Sensing”, CNES - ISPRS, Val d'Isère, 1994, pp. 375-382.

[9] Company A., King C., Beaudoin A., Delpont G., Using microwaves for the assessment of runoff risk over Mediterranean soils: an experiment in the Réart catchment basin (Roussillon, France), in: International Symposium 
"Remote sensing and GIS as tools for monitoring soils in the environment”, Ouagadougou, 1995, pp. 151-167.

[10] Curran P.J., Remote sensing: Using the spatial domain, in: Spatial Statistics for Production Ecology, Wageningen, 1999.

[11] Farrokhnia F., Jain A.K., A multi-channel filtering approach to texture segmentation, in: IEEE Computer Society Conference on Computer Vision and Pattern Recognition, 1991, pp. 364-370.

[12] Guichard F., Morel J.M., Mathematical models in image processing: image iterative smoothing and P.D.E.'s, in: Advanced course on mathematical aspects of image processing, CRM, CVC, Universidad de Barcelona, 1999.

[13] Haralick R.M., Statistical and structural approaches to texture, Proc. IEEE 67 (1979) 786-804.

[14] Hill J., Mehl W., Altherr M., Land degradation and soil erosion mapping in a Mediterranean ecosystem, in: Hill J., Mégier J. (Eds.), Imaging Spectrometry - a Tool for Environmental Observations, Kluwer Academic Publishers, Dordrecht, 1994, pp. 237-260.

[15] Horaud R., Monga O., Vision par ordinateur, outils fondamentaux. Traité des Nouvelles Technologies, série informatique, Hermès, Paris, 1993, 378 p.

[16] Johnson L., Lobitz B., Bosch D., Wiechers S., Williams D., Skinner P., Of pixels and palates: can geospatial technologies help produce a better wine?, in: 1st International Conference on Geospatial Information in Agriculture \& Forestry, Lake Buena Vista FL 1998, ERIM Ann Arbor Michigan.

[17] Le Forner S., Moussa R., Voltz M., Lagacherie P., Andrieux A., Distributed hydrological modelling in agricultural areas with dense ditches network, in: International Conference of the European Geophysical Society, Den Haag, Pays Bas, 1999.

[18] Lennartz B., Louchart X., Voltz M., Andrieux P., Diuron and simazine losses to runoff water in mediterranean vineyards as related to agricultural practices, J. Environ. Qual. 26 (1997) 1493-1502.

[19] Leonard J., Andrieux P., Infiltration characteristics of soil in Mediterranean vineyards in Southern France, Catena 32 (1998) 209-223.

[20] Lillesand T.M., Kiefer R.W., Remote sensing and image interpretation, 4th ed., John Wiley, New York, 1999, $736 \mathrm{p}$.

[21] Louchart X., Transfert de pesticides dans les eaux de surface aux échelles de la parcelle et d'un bassin versant viticole. Étude expérimentale et éléments de modélisation,
Laboratoire de Science du Sol, INRA, ENSAM, Montpellier, 1999, p. 263.

[22] Mallat S., A theory for multiresolution signal decomposition: the wavelet representation, IEEE Trans. Pattern Anal. and Mach. Intell. 11 (1989) 674-693.

[23] Mason D.C., Corr D.G., Cross A., Hogg D.C., Lawrence D.H., Petrou M., Tailor A.M., The use of digital map data in the segmentation and classification of remotely-sensed images, Int. J. Geogr. Inform. Syst. 2 (1988) 195-215.

[24] Minden K.A., Philipson W.R., Grapevine canopy reflectance and yield, in: 8th International Symposium on Machine Processing of Remotely Sensed Data, Purdue University, West Lafayette, Indiana 1982, pp. 430-433.

[25] Niblack W., An introduction to digital image processing, Prentice-Hall Int., London, 1986.

[26] Ruzon M.A., Texture segmentation, an introductory primer, Stanford University, Stanford, 1998.

[27] Serra J., Soille P., Mathematical morphology and its applications to image processing, Kluwer, Dordrecht, 1994.

[28] Skidmore A.K., Bijker W., Schmidt K., Kumar L., Use of remote sensing and GIS for sustainable land management, in: International Conference on Geo-Information for Sustainable Land Management, Enschede, the Netherlands 1997, ITC.

[29] Starck J.-L., Murtagh F., Bijaoui A., Image processing and data analysis, the multiscale approach, 1st ed., Cambridge University Press, Cambridge, 1998, 287 p.

[30] Trolier L.J., Philipson W.R., Philpot W.D., Landsat TM analysis of vineyards in New York, Int. J. Remote Sens. 10 (1989) 1277-1281.

[31] van de Griend A.A., Engman E.T., Partial area hydrology and remote sensing, J. Hydrol. 81 (1985) 211-251.

[32] Wassenaar T., Andrieux P., Baret F., Robbez-Masson J.M., Vineyard identification and description of spatial crop structure by per-field frequency analysis, Int. J. Remote Sens. (2001) in press.

[33] Wildman W.E., Color infrared: a valuable tool in vineyard management, in: 7th Workshop on Color aerial Photography in Plant Sciences and Related Fields, Davis, California 1979, American Society of Photogrammetry, Falls Church, Virginia, pp. 229-238.

[34] Wilkinson G.G., A review of current issues in the integration of GIS and remote sensing data, Int. J. Geogr. Inform. Syst. 10 (1996) 85-101.

[35] Woodcock C.E., Strahler A.H., The factor of scale in remote sensing, Remote Sens. Environ. 21 (1987) 311-332.

To access this journal online: www.edpsciences.org 